\title{
Vapor Phase Hydration of Ethylene Catalyzed by Solid Acids*
}

\author{
by Kozo Tanabe** and .Masahiro Nitta**
}

\begin{abstract}
Summary: The hydration of ethylene over various solid acids such as melal sulfates, phosphates, oxides, solid phosphoric acid and cation exchanged zeolites was investigated in a closed circulation system at $160 \sim 300^{\circ} \mathrm{C}$.

Ferric and aluminum sulfates and zeolites $Y$ showed high catalytic activity in comparison with solid phosphoric acid, $\mathrm{SiO}_{2}-\mathrm{Al}_{2} \mathrm{O}_{3}$, zeolites $\mathrm{A}$ and all other catalysts. The selectivity for ethanol formation was extremely high in metal sulfates and zeolites $\mathrm{A}$, but low in $\mathrm{SiO}_{2}-\mathrm{Al}_{2} \mathrm{O}_{3}$ and zeolites $\mathrm{Y}$. The order of activities of metal sulfates was $\mathrm{Fe}_{2}\left(\mathrm{SO}_{4}\right)_{3}>\mathrm{Al}_{2}\left(\mathrm{SO}_{4}\right)_{3}>\mathrm{Ni}$ $\mathrm{SO}_{4}>\mathrm{Cr}_{2}\left(\mathrm{SO}_{4}\right)_{3}>\mathrm{CuSO}_{4}>\mathrm{MnSO}_{4}>\mathrm{CaSO}_{4}$. The catalysts those acid strength in their dried state was as strong as $-8.2<H_{0} \leqq-3$ were found to be active and selective for ethanol formation. The activities of cation exchanged zeolites $A$ which varied in order of $M g-A>C d-A>$ $\mathrm{Zn}-A>\mathrm{Ca}-A>A g-A>S r-A>\operatorname{La}-A \sim C e-A$ were shown to correlate with the electronegativities of exchanged cations and the adsorption heats of ethylene.

The rate of ethanol formation increased as the mole ratio of $\mathrm{H}_{2} \mathrm{O} / \mathrm{C}_{2} \mathrm{H}_{4}$ decreased. The experiment on the reaction of ethylene with heavy water showed that deuterium did not transfer into ethylene at all. It was concluded by analyzing the kinetic data that the formation of an adsorbed ethyl carbonium ion from an adsorbed ethylene and a proton on acid sites was the rate-determining step of the hydration.
\end{abstract}

\section{Introduction}

The direct synthesis of alcohol from ethylene and water is important in petroleum chemistry and has been extensively studied over various solid acid catalysts such as silicotungustic $\operatorname{acids}^{1) \sim 5)}$, silicophosphoric $\operatorname{acids}^{6}$, solid phosphoric $\operatorname{acids}^{5) \sim 7}$, and metal oxides ${ }^{1,3), 9)}$. However, no study has been made on the correlation between the acidic properties of the catalysts (amount, strength and type of acid sites) and their activities or selectivities.

In the present work, the correlation has been studied by using new catalysts such as metal sulfates, phosphates and zeolites together with some of the well-known catalysts. In the case of cation exchanged zeolites, the correlation of the electronegativities of cations or the adsorption heats of ethylene with the activities or selectivities was also examined. The mechanism of the hydration reaction was discussed on the basis of a kinetic study on the effect of the mole ratio of $\mathrm{H}_{2} \mathrm{O} / \mathrm{C}_{2} \mathrm{H}_{4}$ on the rate of ethanol formation and on the deuterium exchange reaction between ethylene and heavy water.

\footnotetext{
* Received December 8, 1971.

* Department of Chemistry, Facutly of Science, Hokkaido University (Sapporo, Japan)
}

\section{Experimental}

\subsection{Gatalysts and Materials}

Hydrates of metal sulfates of $\mathrm{Ni}, \mathrm{Cu}, \mathrm{Mn}$, $\mathrm{Ca}, \mathrm{Fe}, \mathrm{Cr}$ and $\mathrm{Al}$ (guaranteed or extra pure reagents), $\mathrm{ZnO}$ (guaranteed reagent), $\mathrm{NiO}$ prepared from $\mathrm{NiSO}_{4}, \mathrm{Al}_{2} \mathrm{O}_{3}$ (Wako Junyaku Co., Activated Alumina), $\mathrm{SiO}_{2}-\mathrm{Al}_{2} \mathrm{O}_{3}$ (Nikki Kagaku Co., N631L), $\mathrm{SiO}_{2}-\mathrm{MgO}$ and solid phosphoric acid (both supplied by Mitsui Toatsu Chemicals Co.) were calcined in air at various temperatures for $3 \mathrm{hrs}$. Samples of $10 \sim 20$ mesh were used as catalysts. Aluminum and boron phosphates were prepared from $\mathrm{H}_{3} \mathrm{PO}_{4}$ and $\mathrm{AlCl}_{3} \cdot 6 \mathrm{H}_{2} \mathrm{O}^{10}$ ) and from $\mathrm{H}_{3} \mathrm{PO}_{4}$ and $\mathrm{H}_{3} \mathrm{BO}_{3}{ }^{11}$ ) respectively.

Cation exchanged zeolites $\mathrm{A}$ and $\mathrm{Y}$ were prepared by repeatedly immersing $4 \mathrm{~A}$ pellets and SK-40 powders of the Linde Co. in $1 N$ aqueous solutions of various metal chlorides, nitrate or acetates at $85^{\circ} \mathrm{C}$ and then drying at $120^{\circ} \mathrm{C}$ : after washing with deionized water. The degree of ion exchange was calculated from the amount of unexchanged sodium ion, which was determined by flame spectrometry. The change in crystal structure of zeolite before and after ion exchange, evacuation and hydration reaction was examined by X-ray diffraction.

The ethylene used was C.P. grade reagent of 
99.99\%: purity. Water was deionized water which was degassed by boiling. Heavy water was Merck's reagent of $99.75^{\circ}$ i purity.

\subsection{Measurements of Acidic Property and Heat of Ethylene Adsorption}

Acid amounts of catalysts at various acid strengths were measured by titrating with $0.1 \mathrm{~N}$ $n$-butylamine in benzene, using various indicators ${ }^{12)}$. The measurement was made on dried samples at room temperature, with special attention being paid to minimize the effect of moisture on acidic property ${ }^{13}$. Indicators used were phenylazonaphtylamine $\left(p K_{a}=4.0\right)$, $p$-dimethylaminoazobenzene (3.3), benzeneazodiphenylamine (1.5), dicinnamalacetone $(-3.0)$, benzalacetophenone $(-5.6)$ and anthraquinone $(-8.2)$.

The adsorption heats of ethylene on zeolites were calculated by applying the ClausiusClapeyron's equation to the adsorption isotherms of ethylene. The isotherms were obtained by a constant volume method in the temperature range of $70 \sim 280^{\circ} \mathrm{C}$ and ethylene pressure of $10 \sim 500 \mathrm{mmHg}$. The zeolite samples were evacuated at $400^{\circ} \mathrm{C}$ and $10^{-4} \mathrm{mmHg}$ for $3 \mathrm{hrs}$. The ethylene used in this case was distilled twice.

\subsection{Apparatus and Procedure}

The hydration reaction was carried out at $485 \sim 597 \mathrm{mmHg}$ of ethylene, $23 \sim 132 \mathrm{mmHg}$ of water vapor and $160 \sim 300^{\circ} \mathrm{C}$ in a closed circulation apparatus as shown in Fig. 1. The

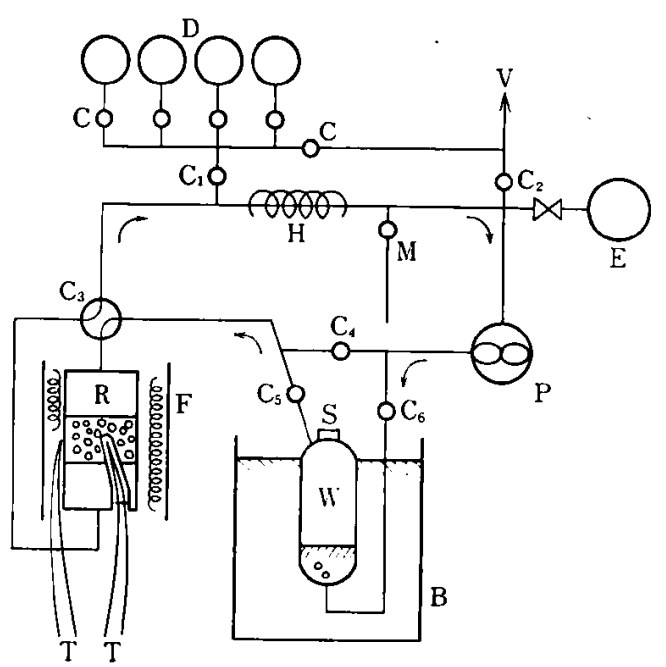

B: Thermostat, C: Cocks, D: Sampling flask for deuterium analysis, E: Ethylene cylinder, F: Electric furnace, $\mathrm{H}$ : Tape heater, $\mathrm{M}$ : Mercury manometer, P: Circulation pump, R: Reaction tube, S: Sampling rubber, T: Thermocouple, $V$ : Vacuum line, W: Water carburetor

Fig. I Closed Circulation Type Reaction Apparatus reaction system (volume : $255 \mathrm{ml}$ ) consisting of a reaction tube $R$ containing $5 \sim 10 \mathrm{~m} l$ of catalyst, a water carburetor $W$ and a circulation pump $P$ was evacuated. After $\mathrm{R}$ attained the desired temperature, cocks $C_{1}, C_{2}$ and $C_{3}$ were closed and ethylene was introduced. Then, $3 \mathrm{ml}$ of water was put into $W$ through sampling rubber $S$ and the vapor pressure of water was kept constant by working $P$. The reaction was started by opening $\mathrm{C}_{3}$ to pass the mixture of ethylene and water through $R$. The vapor pressure of water was controlled by changing the temperature with thermostat $B$. The condensation of water vapor was prevented by wrapping the entire reaction system with a tape heater.

Ethanol and acetaldehyde formed by the reaction dissolve in water in $W$. The aqueous solution is taken up through $\mathrm{S}$ and analyzed at appropriate time intervals by gas chromatography using a $100^{\circ} \mathrm{C}$ column packed with polyethylene glycol 6,000 and hydrogen as carrier gas $(30 \mathrm{~m} l / \mathrm{min})$. The initial rate of ethanol formation $\left(\mathrm{V}_{0}^{\circ} \cdot \mathrm{min}^{-1} \cdot \mathrm{g}^{-1}\right.$; volume $\%$ per unit time and unit weight of catalyst) obtained from a curve of ethanol concentration vs. reaction time was taken as the catalytic activity. In the case of the experiment on the effect of $\mathrm{H}_{2} \mathrm{O} / \mathrm{C}_{2} \mathrm{H}_{4}$ on reaction rate, the rate was obtained from the increase in ethanol concentration in $W$ and in the gaseous phase as described in 3.5 .

The reaction of ethylene with heavy water was carried out over $1.1 \mathrm{~g}$ of nickel sulfate at $220^{\circ} \mathrm{C}, 580 \mathrm{mmHg}$ of ethylene and $23 \mathrm{mmHg}$ of heavy water vapor. The gas samples were collected in flask D at intervals of 2, 7 and 30 min after the start of reaction and ethylene in the sample was analyzed for deuterium content by a Hitachi RMU-6 mass spectrometer at $70 \mathrm{~V}$ of electron accelerating voltage.

\section{Results and Discussion}

\subsection{Correlation between Acidic Property and Catalytic Activity}

In the case of metal sulfate catalysts, only ethanol was formed, with byproducts such as acetaldehyde, diethyl ether or polymer not being detected. The acid amounts of nickel sulfates preheated at various temperatures and their catalytic activities are shown in Fig. 2 . The activities correlate fairly well with the acid amounts at acid strength $\mathrm{H}_{0} \leqq-3$, but not with those at $-3<\mathrm{H}_{0} \leqq 1.5$. It was also 


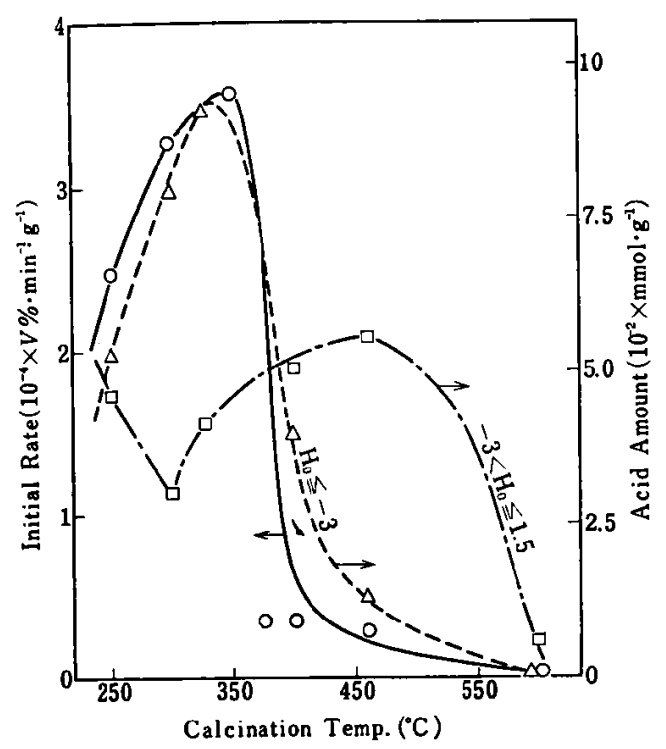

Reaction temp.: $190^{\circ} \mathrm{C}$, Mole ratio of $\mathrm{H}_{2} \mathrm{O} / \mathrm{C}_{2} \mathrm{H}_{4}$ : 0.04 , Total pressure: $620 \mathrm{mmHg}$

Fig. 2 Acidic Property and Catalytic Activity for Ethylene Hydration of Calcined $\mathrm{NiSO}_{4}$

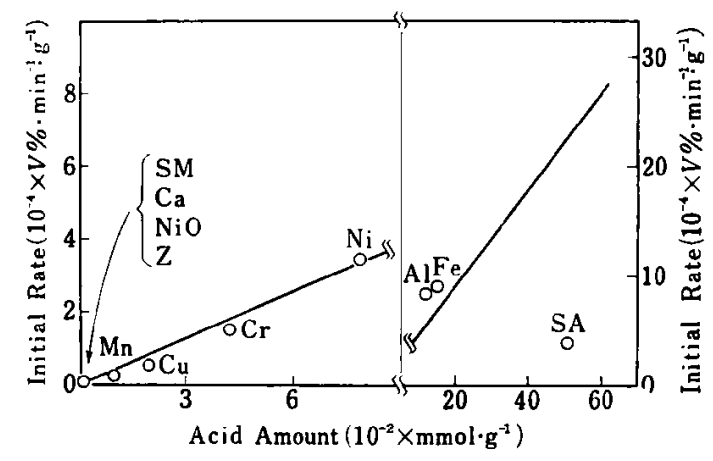

Reaction conditions: the same as those in Fig. 2

$\mathrm{Ni}: \mathrm{NiSO}_{4}, \mathrm{Cu}: \mathrm{CuSO}_{4}, \mathrm{Mn}: \mathrm{MnSO}_{4}, \mathrm{Ca}: \mathrm{CaSO}_{4}$, Cr: $\mathrm{Cr}_{2}\left(\mathrm{SO}_{4}\right)_{3}, \mathrm{Al}: \mathrm{Al}_{2}\left(\mathrm{SO}_{4}\right)_{3}, \mathrm{Fe}: \mathrm{Fe}_{2}\left(\mathrm{SO}_{4}\right)_{3}, \mathrm{SA}$ : $\mathrm{SiO}_{2}-\mathrm{Al}_{2} \mathrm{O}_{3}, \quad \mathrm{SM}: \mathrm{SiO}_{2}-\mathrm{MgO}, \mathrm{NiO}: \mathrm{NiO}, \mathrm{Z}: \mathrm{ZnS}$

Fig. 3 Acid Amount at $\mathrm{H}_{0} \leqq-3.0$ and Catalytic Activity for Ethylene Hydration of Various Solid Acids

found that there was no correlation between the activities and the acid amounts at $1.5<\mathrm{H}_{0} \leqq$ $3.3,3.3<\mathrm{H}_{0} \leqq 4.0, \quad \mathrm{H}_{0} \leqq 1.5$ or $\mathrm{H}_{0} \leqq 4.0$. In Fig. 3, the activities of various solid acids are plotted against the acid amounts at $\mathrm{H}_{0} \leqq-3$. A linear relationship was found. The facts seem to indicate that the active sites for ethanol formation are acid sites of $\mathrm{H}_{\mathbf{0}} \leqq-3$. The activation energy of ethanol formation catalyzed by nickel sulfate heat-treated at $300^{\circ} \mathrm{C}$ was $22 \mathrm{kcal} / \mathrm{mol}$.

It was reported previously that both Brönsted and Lewis acid sites were formed on the surface of heat-treated nickel sulfate and that the maxi- mum of Brönsted acidity appeared when heattreatment was at $250^{\circ} \mathrm{C}$ and the maximum of Lewis acidity at $400^{\circ} \mathrm{C}^{14)}$, while the sum of both acidities was maximum at $350^{\circ} \mathrm{C}^{15}$. Since the maximum activity of nickel sulfate for ethanol formation was observed at $350^{\circ} \mathrm{C}$ and the activity curve correlated well with the Bronsted plus Lewis acidity curve as shown in Fig. 2, the ethanol formation is considered to be catalyzed by both Brönsted and Lewis acid. However, Lewis acid sites on dehydrated nickel sulfate may be converted to Brönsted acid sites when water vapor is present during reaction. The conversion takes place certainly by the addition of water at room temperature ${ }^{14)}$, although it is not clear whether it does at high temperature. It is confirmed that water vapor does not affect the acid strength of $\mathrm{H}_{0} \leqq-3$ on the surface of dired catalyst, if temperature is higher than $80^{\circ} \mathrm{C}^{16)}$.

\subsection{Acidic Property and Selectivity}

The activity for ethanol formation of silicaalumina, which has a comparatively large acid amount at $\mathrm{H}_{0} \leqq-3$, was found to be much lower than that expected from the linear relation indicated in Fig. 3. Acetaldehyde was also formed in addition to ethanol and the formation of ethylene polymer is suggested from the large decrease in pressure. These are considered to be due to the existence of very strong acid sites of $\mathrm{H}_{\mathbf{0}} \leqq-8.2$ on the catalyst. In fact, acetaldehyde and ethylene polymer were also formed over the catalysts of alumina and aluminum phosphate which have strong acid sites of $\mathrm{H}_{0} \leqq$ -8.2 , but not over solid phosphoric acid and boron phosphate which have no such strong acid sites, as shown in Table 1. These results combined with those mentioned in 3.1 indicate that the acid strength of active sites for ethanol formation is $-8.2<\mathrm{H}_{0} \leqq-3$. The effective acid strength for the hydration of propylene was reported by Ogino $^{17}$ to be $-3<\mathrm{H}_{0} \leqq+1.5$ under the reaction conditions of $160 \sim 220^{\circ} \mathrm{C}$. and $5 \mathrm{~atm}$. The acid strength is quite weak compared with that for the hydration of ethylene. The difference can be attributed to the higher basic strength of propylene.

\subsection{Activity and Selectivity of Zeolites}

The activities of cation exchanged zeolites A and $\mathrm{Y}$ for the hydration of ethylene are shown in Table 2. Be-A, Ba-A, H-A and Cu-A, whose crystal structure was destroyed by cation ex- 
Table 1 Selectivity of Catalysts

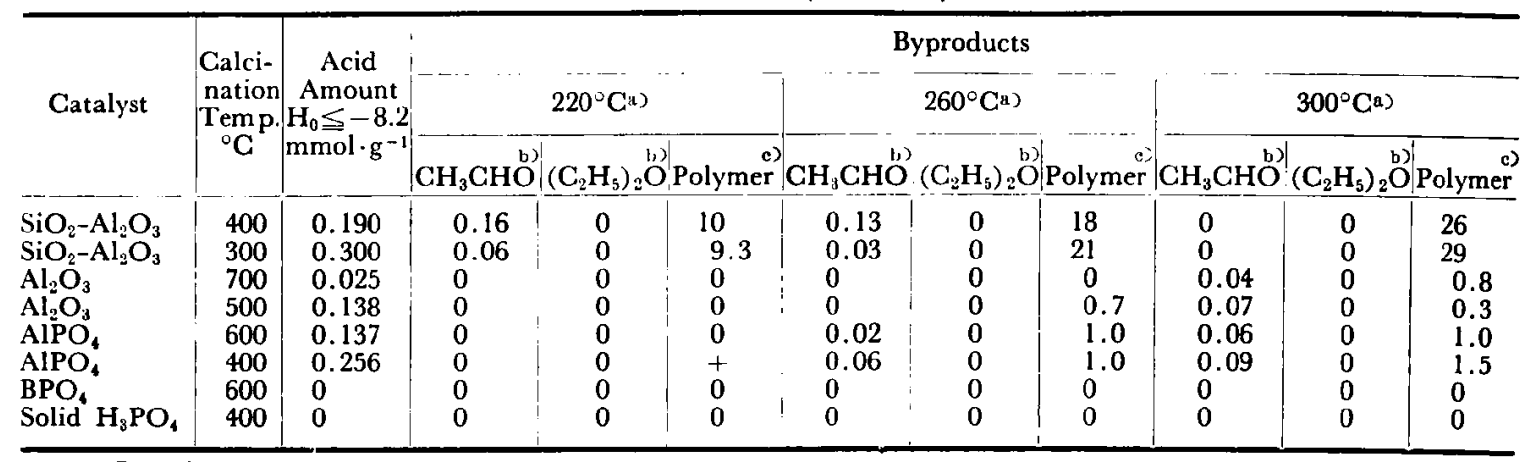

a) Reaction temperature.

b) Peak height ratio in gas chromatogram of acetaldehyde or diethyl ether to ethanol after $3 \mathrm{hrs}$.

c) Pressure decrease, $\mathrm{mmHg} \cdot \mathrm{g}^{-1}$, after $3 \mathrm{hrs}$.

Table 2 Various Properties and Catalytic Activities of Cation Exchanged Zeolites A and Y

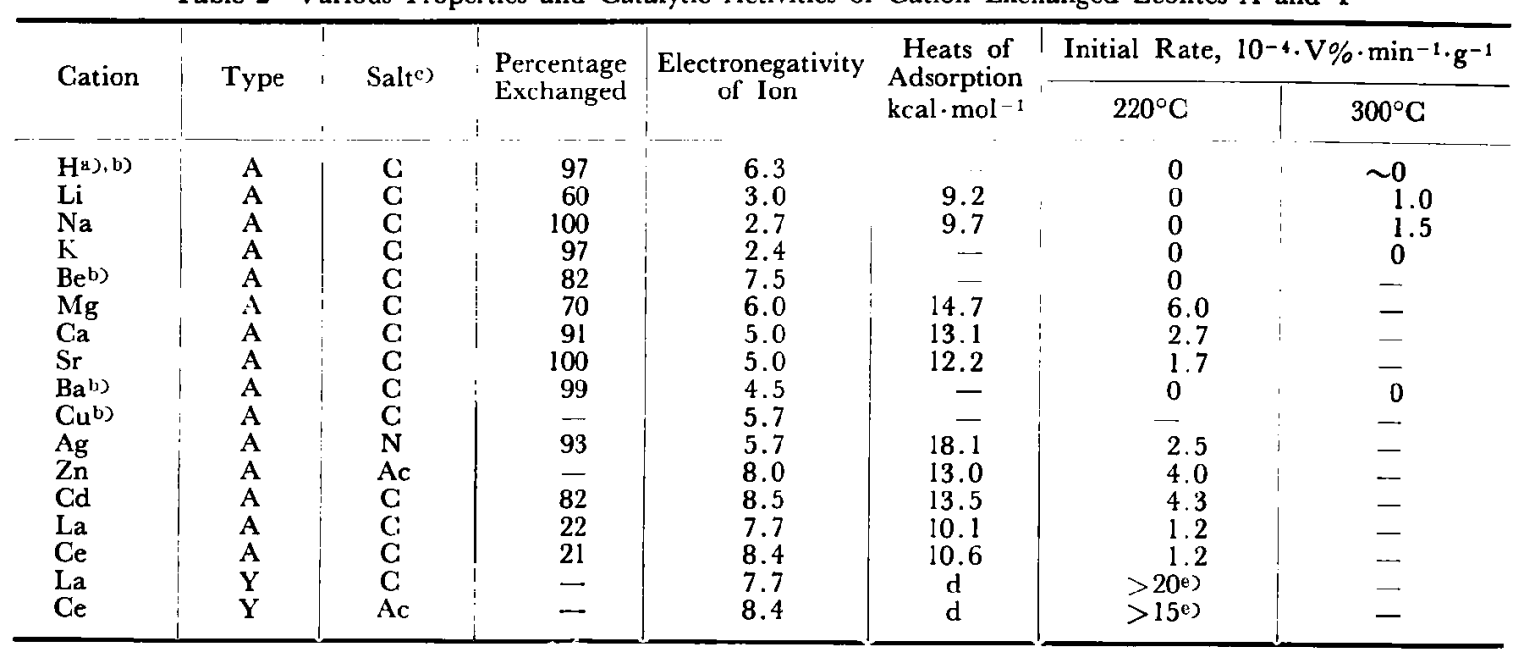

a) Prepared by heat-treating Zeolite $\mathrm{A}$ exchanged with $\mathrm{NH}_{4}{ }^{+}$.

b) Crystal structure was collapsed.

c) Salt used for ion exchange, $\mathrm{C}:$ Chloride, $\mathrm{N}$ : Nitrate, Ac : Acetate.

d) Unmeasurable due to simaltaneous occurrence of polymerization.

e) Polymerization took place besides hydration.

change or evacuation, showed no activity. The active cation exchanged zeolites A (except Ag-A) yielded only ethanol as a reaction product and little pressure decrease was observed during the reaction over the catalysts. However, Ag-A, which crystal structure was destroyed during the reaction, and zeolites $Y$ yielded acetaldehyde together with ethanol and brought about a large decrease in pressure (from 600 to 470 $\mathrm{mmHg}$ in $10 \mathrm{~min}$ for $\mathrm{Ag}-\mathrm{A}$ and from 610 to $585 \mathrm{mmHg}$ in $10 \mathrm{~min}$ and from 610 to $335 \mathrm{mmHg}$ in $1 \mathrm{hr}$ for zeolites $\mathrm{Y}$ ), which indicates the formation of ethylene polymer. These results can be interpreted by taking into account the difference in pore sizes of the zeolites. Since the pore size of zeolites A exchanged with cations is $3 \sim 5 \AA$, large molecules such as polymer cannot be formed even if the zeolites have strong acid sites of $\mathrm{H}_{0} \leq-8.2$ active for polymerization. However, with zeolites $Y$, which have a larger pore size (ca. $9 \AA$ ), it is possible to yield products of large molecules. The large pressure decrease in the case of Ag-A seems to be due to the formation of large pores by collapse of the crystal structure during the reaction as observed by $\mathrm{X}$ ray diffraction.

\subsection{Active Site on Zeolites A}

Three kinds of active sites are reported for cation exchanged zeolites; namely, 1) protonic hydroxyl group polarized by cation ${ }^{18)}$, 2) proton formed by dissociation of coordinated water on cation ${ }^{19}$ ) and 3) electrostatic field formed between cation and $\left(\mathrm{AlO}_{4}\right)^{-}$in zeolite frame ${ }^{20)}$. Under the present reaction condition where water vapor is present, proton formation according to the following formula seems to be 


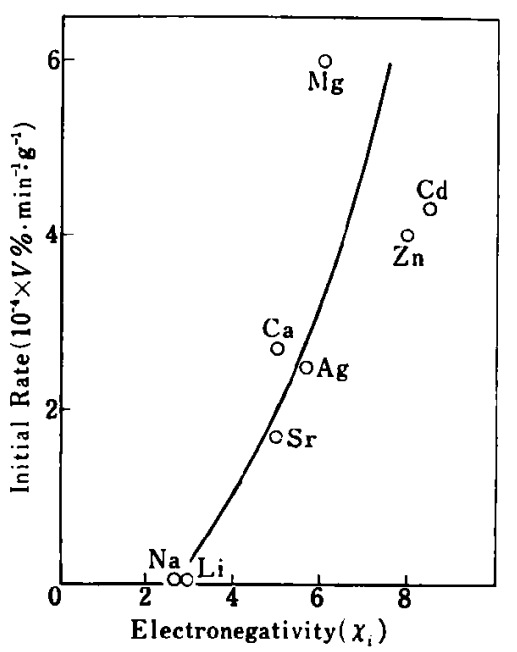

Fig. 4 Relation of Catalytic Activity of Cation Exchanged Zeolites A with Electronegativity of Cation

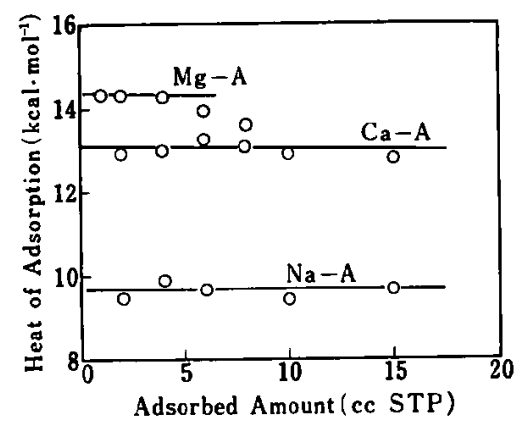

Fig. 5 Heats of Adsorption of Ethylene on Zeolites A

reasonable.

$$
\mathrm{M}^{n+}+\mathrm{H}_{2} \mathrm{O} \longrightarrow[\mathrm{M}(\mathrm{OH})]^{(n-1)+}+\mathrm{H}^{+}
$$

A linear relationship between the logarithm of the equilibrium constants of the above reactions, i.e., acid strength and the electronegativities of cations, $\chi_{1}$, is reported by Tanaka et al. ${ }^{21}$ In the present work, the activities of cation exchanged zeolites A for ethanol formation were shown to correlate with the electronegativities of cations (Fig. 4). The large deviations in La-A and Ce-A seem to be due to a very small percent of the exchanged cations (see Table 2). Therefore, the active sites are considered to be Brönsted acid as in (2). The observed independency of adsorption heat of ethylene on the adsorbed amount (Fig. 5) suggests that the active sites are homogeneous.

If basic ethylene is adsorbed on acid sites on the catalyst surface, the stronger the acid strength of the site is, the higher the heat of adsorption is. The adsorption heat may be a measure for the acid strength of zeolite $A$ which cannot be mea-

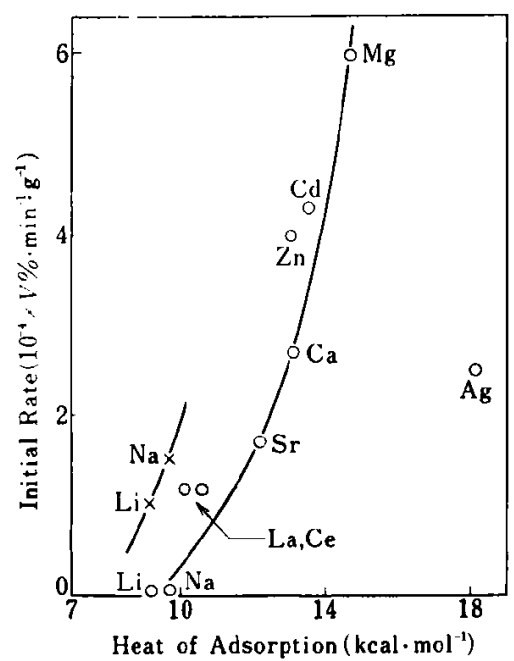

Reaction temp.: $\bigcirc 220^{\circ} \mathrm{C}, \times 300^{\circ} \mathrm{C}$

Fig. 6 Relation of Catalytic Activity of Cation Exchanged Zeolites A with Heat of Adsorption of Ethylene

sured by the usual $n$-butylamine titration method using Hammett indicators, because of colored material having small pore size. Since ethylene is known to adsorb on the cation of zeolite in the absence of water ${ }^{22}$, the heat of adsorption increases with increasing electronegativity of cations. If water is present, a cation of stronger electronegativity dissociates the water molecule more easily to form a proton. Hence, the adsorption heat is to increase with increase in acid strength of Brönsted acid site and the catalytic activity is expected to increase with increase in the heat of adsorption. Fig. 6 shows a fairly good correlation between the catalytic activities of cation exchanged zeolites A for ethanol formation and the heat of adsorption. The large heat of adsorption observed in Ag-A is due to the fact that $\mathrm{Ag}^{+}$has a tendency to form a complex with olefin more easily than other cations $^{22), 23)}$, because of the interaction between $5 \mathrm{sp}$ orbital of $\mathrm{Ag}^{+}$and $\pi$ electron of ethylene and between $4 \mathrm{~d}$ electron of $\mathrm{Ag}^{+}$and $\pi *$ orbital of ethylene. The nature of $\mathrm{Ag}^{+}$may account for the deviation from the curve in Fig. 6.

The heats of adsorption of ethylene on zeolites A (except Ag-A) were below $15 \mathrm{kcal} / \mathrm{mol}$ as shown in Table 2. The heat of adsorption of water on zeolites A is estimated to be much larger than that of ethylene, since the basic strength of water is higher than that of ethylene and, in fact, the adsorption heat of water on zeolites $\mathrm{Y}$ exchanged with $\mathrm{Ca}^{+}$and $\mathrm{La}^{+}$is reported to be $30 \sim 40 \mathrm{kcal} / \mathrm{mol}$ at $20 \sim 195^{\circ} \mathrm{C}^{24}$ ). 


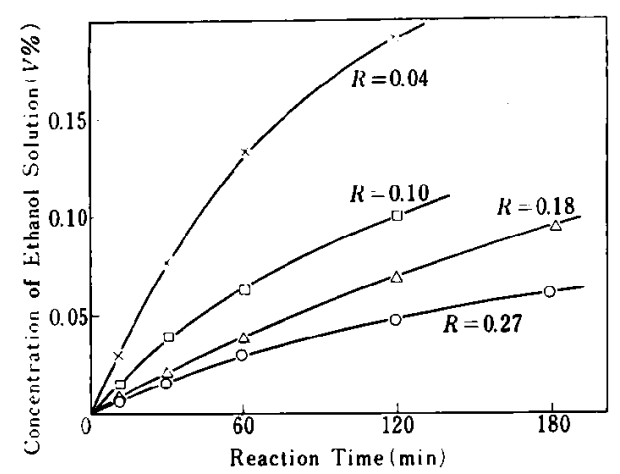

Reaction temp.: $220^{\circ} \mathrm{C}$, Total pressure: $620 \mathrm{mmHg}$, R: mole ratio of $\mathrm{H}_{2} \mathrm{O} / \mathrm{C}_{2} \mathrm{H}_{4}$, Catalyst: $\mathrm{NiSO}_{4}$ heattreated at $300^{\circ} \mathrm{C}$

Fig. 7 Ethanol Concentration vs. Reaction Time

Therefore, it is likely that water is preferentially adsorbed on the cation of the zeolite and a proton as an active site is formed. This agrees with the view discussed above on the basis of the correlation between the electronegativity of the cation and the catalytic activity.

\subsection{Mechanism of Hydration}

The mechanism of the hydration of ethylene is discussed here on the basis of the experimental results of the effect of the mole ratio of $\mathrm{H}_{2} \mathrm{O}$ / $\mathrm{C}_{2} \mathrm{H}_{4}$ on the reaction rate and of the deuterium exchange reaction of ethylene with heavy water.

Fig. 7 shows the plot of the concentration of ethanol in aqueous solution against reaciton time. The concentration of ethanol formed increases as the mole ratio $R$ of $\mathrm{H}_{2} \mathrm{O} / \mathrm{C}_{2} \mathrm{H}_{4}$ is decreased from 0.27 to 0.04 . The data of Fig. 7 were analyzed as below by applying the HougenWatson's rate equations ${ }^{25}$ ) to determine the ratedetermining step of the hydration reaction. For the analysis, the reaction rate $r$ was obtained as the sum of $r_{1}$ and $r_{2}$, where $r_{1}$ and $r_{2}$ are the rates of ethanol formation in the water carburetor and in the gaseous phase, respectively. Values for $r_{1}$ and $r_{2}$ were obtained by the equations $r_{1}=d n_{l} / d t$ and $r_{2}=d n_{g} / d t$, where $n_{l}$ and $n_{g}$ are molar concentrations of ethanol in the liquid and gaseous phase, respectively. The value of $n_{g}$ was obtained from the partial pressure of ethanol in equilibrium with the ethanol solution, which was calculated by using gas-liquid equilibrium data ${ }^{26)}$ of water-ethanol system. It was ascertained that the partial pressure of ethanol vapor coming from the water carburetor was in equilibrium with liquid ethanol and almost equal to the partial pressure of ethanol vapor before entering the carburetor.
Now, if we assume that ethanol formation takes place on the catalyst surface and the reaction rate is controlled by a surface reaction between adsorbed ethylene and water molecules, the reaction rate $r$ is expressed by the equation ${ }^{25)}$.

$$
r=\frac{Z K_{E} K_{W}\left(P_{E} P_{W}-P_{A} / K_{P}\right)}{\left(1+K_{E} P_{E}+K_{W} P_{W}+K_{A} P_{A}\right)^{2}}
$$

where $P_{E}, P_{W}$ and $P_{A}$ are partial pressures of ethylene, water and ethanol, $K_{E}, K_{W}$ and $K_{A}$ adsorption equilibrium constants of ethylene, water and ethanol, and $K_{P}$ and $Z$ equilibrium constant of reaction and constant, respectively.

If the total pressure, $P$, (the sum of $P_{E}$ and $P_{W}$ ) is kept constant, $P_{E}=P /(1+R)$ and $P_{W}=P R /$ $(R+1)$. Assuming $P_{A}=0$ at the initial stage of reaction, the initial rate $r_{0}$ is expressed by the equation.

$$
r_{0}=\frac{Z K_{E} K_{W} R P^{2}}{\left(1+R+K_{E} P+K_{W} P R\right)^{2}}
$$

where $r_{0}$ is obtained by extrapolation of $r$ to $t=0$.

Equation (2) can be writen as follows.

$$
\left(\frac{R}{r_{0}}\right)^{1 / 2}=\frac{1+K_{W} P}{\left(Z K_{E} K_{W}\right)^{1 / 2} \cdot P} \cdot R+\frac{1+K_{E} P}{\left(Z K_{E} K_{W}\right)^{1 / 2} \cdot P}
$$

If the surface reaction (step III in scheme (4)) is the rate-determining step, the plots of $\left\langle R^{\prime}\right.$ $\left.r_{0}\right)^{1 / 2}$ against $R$ should lie on a straight line. Fig. 8 shows that the plots give a good straight line. However, the data of Fig. $7 \mathrm{did}$ not fit any equations derived by assuming that the rate-determining step is adsorption of ethylene or water (step I or II), desorption of adsorbed ethanol (step IV), reaction of adsorbed ethylene with free water, or reaction of adsorbed water

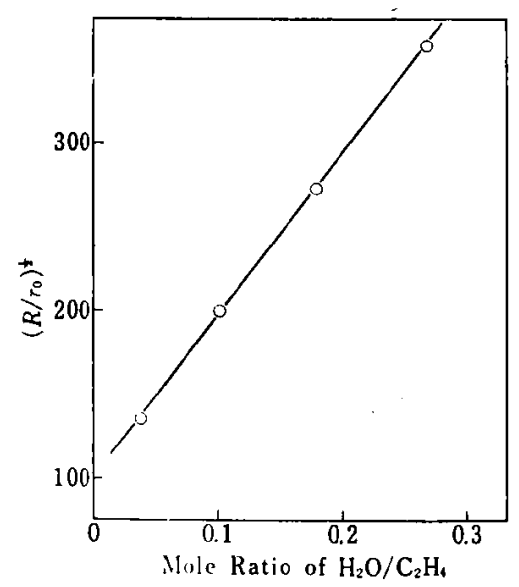

Reaction temp.: $220^{\circ} \mathrm{C}$, Total pressure: $620 \mathrm{mmHg}$, Catalyst: $\mathrm{NiSO}_{4}$ heat-treated at $300^{\circ} \mathrm{C}$

Fig. 8 Plot of Equation (3)

Bulletin of The Japan Petroleum Institute 
with free ethylene.

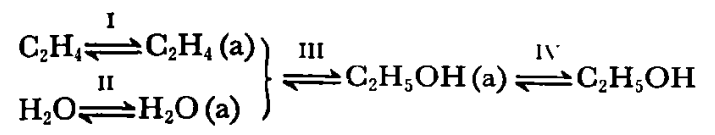

It was concluded from these results that the rate-determining step was the surface reaction of adsorbed ethylene and water molecules (step III). Since it is generally accepted that hydration of olefin catalyzed by acids in a homogeneous liquid phase proceeds by nucleophilic attack of the hydroxyl ion to carbonium ion formed by addition of a proton to the olefin ${ }^{27)}$, the hydration on a solid surface may also be considered to proceed via the ethyl carbonium ion. Thus, step III in scheme (4) may be written more in detail as follows.

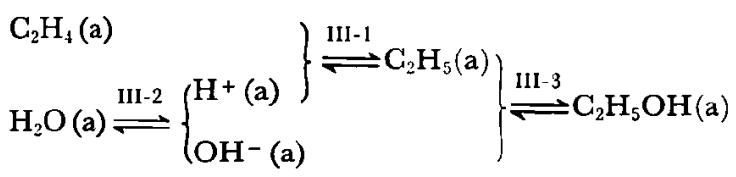

The detailed rate-determining step will be discussed below in the light of the observed results of the deuterium exchange reaction between ethylene and heavy water. The mass spectra of ethylene remaining during the reaction under the experimental conditions described in 2.3 showed no peak at mass numbers 30 , 31 and 32 and a very small peak at 29 . The ratio of peak height at 29 to that at 28 was the same as that of ethylene before use for the reaction. These results indicate that no $\mathrm{C}_{2} \mathrm{H}_{3} \mathrm{D}$, $\mathrm{C}_{2} \mathrm{H}_{2} \mathrm{D}_{2}, \mathrm{C}_{2} \mathrm{HD}_{3}$ or $\mathrm{C}_{2} \mathrm{D}_{4}$ is formed. The fact that the deuterium in heavy water did not transfer to ethylene indicates that either step $I$ in (4) or III-1 in (5) must be a rate-determining step, because, if any of steps II, IV, III-2 and III-3 is rate-determining, steps I and III-I are in equilibrium and, therefore, deuterium exchange should be observed. Since, however, step I is not the rate-determining step as described above, it is concluded that step III-1 is the ratedetermining step of the hydration.

\section{Acknowledgments}

The authors wish to thank Dr. I. Matsuzaki and Dr. H. Hattori for their cooperations and helpful discussions.

\section{References}

1) Mace, C. V., Bonilla, C. F., Chem. Eng. Prog., 50, (8), 385 (1954).

2) Muller, J., Waterman, H. I., Brenstof-Chem., 38, 321 (1957).

3) Imai, T., Yoshinaga, Y., Koatsu Gasu, 27, (6), 212 (1963).

4) Kurita, M., Hosoya, T., Uchida, H., Imai, T., Yoshinaga, Y., Tokyo Kogyo Shikensho Hokoku, 61, (6), 218 (1966).

5) Kuribayashi, H., Kugo, M., J. Chem. Soc. Japan, Ind. Chem. Sect., 69, (10), 1930, 1935 (1966).

6) Wagner, C., U. S. 2,876,266 (1959).

7) Uemaki, O., Yanai, I., Fujikawa, M., Kugo, M., J. Chem. Soc. Japan, Ind. Chem. Sect., 73, (10), 2142 (1970).

8) Sanders, F. J., Dodge, B. F., Ind. Eng. Chem., 26, (2), 208 (1934).

9) Bliss, R. H., Dodge, B. F., ibid., 29, (1), 19 (1937).

10) Kearby, K., "Actes du Deuxième Congrès Intern. de Catalyse", Paris, 1960, Sect. III-134.

11) Riharz, W., Lutz, M., Guyer, A., Helv. Chim. Acta, 42, 2212 (1959).

12) Johnson, O., J. Phys. Chem., 59, 827 (1955).

13) Matsuzaki, I., Fukuda, Y., Kobayashi, T., Kubo, K., Tanabe, K., Shokubai (Tokyo), 11, (6), 210 (1969).

14) Hattori, H., Miyashita, S., Tanabe, K., Bull. Chem. Soc. Japan, 44, (4), 893 (1971).

15) Tanabe, K., Ohnishi, R., J. Res. Inst. Catalysis, Hokkaido Univ., 10, (3), 229 (1962).

16) Matsuzaki, I., Nitta, M., Tanabe, K., J. Res. Inst. Catalysis, Hokkaido Univ., 17, (1), 46 (1969).

17) Ogino, Y., Shokubai (Tokyo), 4, (1), 73 (1962); J. Catalysis, 8, (1), 64 (1967).

18) Richardson, J. T. J. Catalysis, 9, (2), 172 (1967).

19) Ward, J. W., ibid., 14, (4), 365 (1969).

20) Pickert, P. E., Rabo, J. A., Dempsey, E., Schomaker, V., "Proc. Intern. Cong. Catalysis", 3rd, Amsterdam, I, 714 (1964).

21) Tanaka, K., Ozaki, A., Tamaru, K., Shokubai (Tokyo), 6, (4), 262 (1964); Tanaka, K., Ozaki, A., J. Catalysis, 8, (1), 1 (1967).

22) Carter, J. L., Yates, D. J. C., Lucchesi, P. J., Elliott, J. J., Kevorkian, V., J. Phys. Chem., 70, (4), 1126 (1966).

23) Dewar, M. J. S., Bull. Soc. Chim. France, 18, C 71 (1951).

24) Dmitriev, R. V., Kalyaev, G. I., Bronnilov, O. D., Minachev, Kh. M., Kinetika $i$ Kalaliz, 11, (6), 1525 (1970).

25) Hougen, O. A., Watson, K. M., Ind. Eng. Chem., 35, (5), 529 (1943).

26) Wremsky, M., Z. Physik. Chem., 81, 1 (1912).

27) Taft, R. W., J. Am. Chem. Soc., 74, (21), 5372 (1952). 